\title{
Organizational Culture, Individual Innovation and their relation to Nursing Staff's Work Engagement
}

\author{
1Eman Saad El Desoky, 2 Naglaa Mohamed El Said, 3 Ahlam Mahmoud El-Shaer \\ 1 Demonstrator of Nursing Administration, Faculty of Nursing - Beni-Suef University, \\ 2 Lecturer of Nursing Administration, Faculty of Nursing - Beni-Suef University, 3 Assistant Professor \\ of Nursing Administration, Faculty of Nursing - Mansoura University
}

\begin{abstract}
Background: Organizational culture supports nursing staff in their organization and significantly improves their individual innovation and work engagement.Aim: Investigating organizational culture, individual innovation and their relation to nursing staff's work engagement. Methods: A descriptive, correlational study design was conducted with a convenient sample of (185) nursing staff at Kafr El Sheikh University Hospital. Data was collected using an Organizational Culture Assessment Instrument, Individual Innovation Scale and Utrecht Work Engagement Scale. Results: Confirmed that majority of nursing staff have high level of perception about organizational culture, more than half of them had highly innovative level and more than two third of nursing staff have high level of work engagement. There was highly statistically significant positive correlations were found between organizational culture and individual innovation with work engagement. Conclusion: It was concluded that nursing staff at Kafr El Sheikh Hospital had high perception of organizational culture, highly innovative level and had high level of work engagement. Recommendations: The study recommended that incorporate culture in the hospital policy by giving the chance to every staff in the hospital to participate in decision making. Provide training programs about the importance of creativity for enhancing hospital ability and efficiency, and how mangers can use their problem solving styles effectively. Develop a mentorship program where more experienced nursing staff act as models and mentors to the new nursing staff in the profession to empower and motivate them to remain in their work.
\end{abstract}

Keywords: Organizational culture, Individual Innovation, Work engagement. 
1Eman Saad El Desoky' et. al.

\section{Introduction}

The maintenance of a healthy work atmosphere and culture assume vital importance in the lifespan of an organization. Certainly, a healthy work culture not only supports the day to day work of the organization but also associates with mission to nursing service policies, goals and staff performance and their ability to innovate in the organization and their readiness to work. Furthermore, work engagement is considered one of the most important entraining elements for organizational accomplishment (Elewa, \& El Banan, 2019).

Nursing staff spend more of their hours at work, their organization's culture affects both their work lives as well as their personal lives. The culture is an influential factor in the success of the organization. Organizational culture refers to the principles, beliefs, philosophies and values that the staff of an organization share (Kamel, \&Aref, 2017).

Culture is a typical of norms, beliefs, values and attitudes which affects organizational behavior. Organizational culture reflects shared and learned values, principles and attitudes of their staff. It was states toward a method of shared meaning held by the staff that distinguishes the organization from others. Organizational culture was important element which highly influences the nursing staff commitment, job satisfaction, engagement and retention (Kerns, 2020).

The organizational culture provides convention values of general criteria and standards that guide principles of nursing staff employ to elect types of behaviors as desirable or undesirable. Organizational culture controls how their staff makes decisions, understand and manage their organizational environment

\section{(Christensen, \&Rovik, 2020).}

Organizational culture can successfully promote the involvement of team work in the innovative process that can be improving satisfaction to the activity and initiative of them. Organizational cultures recommended as progress innovation and constructing suitable conditions for performing that are characterized by dynamism, flexibility, fast adaptation to changing conditions and non-stereotypical solutions. A key toward the progress of innovation in an organization is support and reassurance for every nursing staff to seek and discover substitute, nonstandard methods of accomplishing objectives and performing tasks (Greer, \& Hobson, 2020).

One of different way that deal with adopting a strategies of innovativeness culture so the staff can create ideas and share those ideas so that strategy and policy can be implemented. Individuals who feel imaginative and innovative have been found to be more persistence to task completion. Once the task is accomplished, the staffs have a sense of pride and a sense of contribution to the organization. Innovation can support a hospital dealing with problems (Weng, Huang, Chen, \& Chang, 2015). Innovation states as the manner that an individual or organization assumes to conceptualize trademark innovative services, processes and ideas, or to approach existing services, processes and ideas in new ways. Innovation is also the manner of generating and applying a new idea. It is the process of attractive valuable ideas and adapting them into valuable products, services, methods and 
processes of operation. These valuable ideas are the outcome of creativeness which is the essential for innovation. Creativeness is responsible for new ideas for quality enhancement in organizations and innovation sets these thoughts into action (Snihur, \&Wiklund, 2019).

Organizational success influenced by the capacity of innovative ideas that implemented and achieves accomplishment to get support in the organization. The role of innovation in improving organizational productivity and efficacy that is vital important within the pressures of growing global competition (Taylor,\&Hynes,2019). Innovative behavior is deliberate introduction by the staff of novel ideas, services and procedures in the role of work or within the structure of the organization and this attitude is positively impact on work engagement. The work engagement is considered as an element that encourages positive outcomes in management firms. Likewise, when the staff considers that his/her opinion is valued, he/she is more involved with the management process, which allows the improvement of tasks and targets within the organization (Le Blanc, \& Wang, 2020).

Work engagement is a positive behavior or a positive state of mind at labor that leads to positive work-related outcome. Staff with great levels of work engagement is enthusiastic and dedicated to their work and engrossed to their work (Bakker, \&Tims, 2020).

Basically, work engagement captures in what way employees put their experience at work: as inspiring and enthusiastic and something to which they really need to commit time and effort (the vigor component) as a significant and meaningful pursuit (dedication) and as engrossing and they are fully focused (absorption) (Kuijpers, \& van Woerkom, 2020).

Work engagement, an indicator of work motivation, is one route to improve the experiences of healthcare workers that allow to the staff to innovate that improve atmosphere of work and sustain organizational culture (Abou Hashish, \&Mousa, 2018).

Work engagement and efficiency could demonstrate to be an excellent parameter to assess the health of the organization as such with concerns to satisfaction, innovation, commitment, retention and productivity. Organizations that are perceived to have a positive organizational culture tend to offer rewards to their nursing staff which in turn leads to improve creativity of an environment that is empowering and allowing employees to grow, develop and function at their utmost potential Rai, \&Maheshwari, (2020) so the present study aimed to investigate organizational culture, individual innovation and their relation to nursing staff's work engagement.

\section{Significance of study:}

The vast amount of research found in the literature indicates that nursing staff work engagement has been in the mind of scholars and practitioner who seek a solution to increase productivity. However, nursing staff engagement continues to be explored due to the amount of positive outcome which brings to the organization. Nevertheless, there is little studies of the impact that innovation has on nursing staff work engagement (Anderson, et al, 2014).

Organizational culture can encourage or discourage a variety of behaviors and decisions including those related to innovation. Thus it is important to use the organization culture to mobilize and motivate nursing staff to 
be creative and innovative and engaged in their work (Kamel \& Aref ,2017). So, this study aims to investigate organizational culture, individual innovation and their relation to nursing staff's work engagement at Kafr El Sheikh University Hospital.

\section{Aim of the study}

This study aimed to investigate organizational culture, individual innovation and their relation to nursing staff's work engagement at Kafr El Sheikh University Hospital.

Research questions:-

RQ1: What is the level of nursing staff's perception of organizational culture?

RQ 2: To what extent nursing staff are innovative?

RQ 3: What is the level of nursing staff's work engagement?

RQ4: What is the relation of organizational culture and individual innovation with nursing staff's work engagement?

\section{Subject and Methods}

Study design:

The research design utilized a quantitative, descriptive design.

\section{Study setting:}

This study was conducted at Kafr

El Sheik University Hospital. The hospital was fully operational in February 2017 that provides a wide spectrum of health service at delta region. It is equipped with the recent international equipment \& instruments, the total beds capacity equal 365 beds.

\section{Study subjects:}

The participants of present study was include all nursing staff who are available during the time of data collection and nursing staff who have experience at least one year and willing to participate in this study. Total numbers were (185) nursing staff.
Tools of data collection:

The data of this study was collected by using three tools:-

Tool (I) Organizational Culture Assessment Instrument (OCAI).

This tool adopted from (Polit, Beck, \&Hungler, 2001) and aimed to assess nursing staff perception about organizational culture.

It consists of two parts:-

Part (1) Demographic characteristic of nursing staff as (age -education qualification -Year of experience- Job title-Gender and Marital status).

Part (2) It consists of (24) items covers six dimensions namely (Dominant Characteristics -Organizational Leadership -Management of Employees Organization Glue -Strategic Emphases Criteria of Success).Each dimension has four statements. Responses measured with five- points Likert scale ranging from 1 (Strongly Disagree) to 5 (Strongly Agree).

\section{Scoring System:}

Classified as following:

- High (88-120).

- Moderate (56-87).

- Low (24-55). (EIgamal,2018).

Tool (II) Individual Innovation Scale.

This tool adopted from (Hurt, et al, 2013) and aimed to assess individual innovation in the organization. It consist of 20 statement covers four dimensions (Openness to Experience (5 items) -Prime Mover Originator (5 items) - Readiness to Change (8 items) -Taking Risks (2 items) ). Each Responses measured with five-points likert scale ranging from 1 (Strongly Disagree) to 5 (Strongly Agree).

Scoring System

Classified as following:

- Score above 80 are classified as Innovators. 
- Scores from 69 to 80 are classified as Early Adopters

- Scores from 57 to 68 are classified as Early Majority.

- Scores from 46 to 56 are classified as Late Majority.

- Score below46are classified Laggards \&Traditionalists.

- In general nursing staff who score above 68 are classified as highly innovative, and score below 64 are classified as low in innovativeness and score between (64 -68) are classified as moderate in innovation. (Hurt, et al, 2013).

Tool (III) Utrecht Work Engagement Scale (UWES).

This tool adopted from (Schaufeli ,et al., 2006) and aimed to assess nursing staff' Work Engagement Scale (UWES), It consists of (17) items covers three dimensions namely (Dedication (5 items)-Vigor (6 items) and Absorption (6 items) ). Responses measured with five-points Likert scale ranging from 0 (Never) to 4 (Always).

Scoring System

Classified as following:

- Higher work engagement score (46-68)

- Moderate work engagement score (24-45)

- Lower work engagement score (0-23). (Shaheen , 2018).

Validity of the study tools:

tools translated by researcher into

Arabic and tested for its content validity and relevance by a panel of five expertise from Faculties of Nursing: Beni-Suef, Tanta ,Mansoura and Kafr El Sheikh University who revised the tools for clarity, ,applicability, comprehensiveness, understanding, relevancy and ease for implementation and according to their opinions ,modifications were applied. The modifications were related to grammatical language and rephrasing of some sentences and modifying individual innovation scale to Four dimensions according jury committee modification namely (Openness to Experience (5 items) -Prime Mover Originator (5 items) - Readiness to Change (8 items) -Taking Risks (2 items).

Reliability of the study tool:

Reliability test of the study tools, organizational culture, individual innovation, nursing staff work engagement, were tested by Cranach's Alpha. Reliability was computed and found (0.94), (0.72), (0.91) respectively.

Pilot study:

A pilot study was carried out on nursing staff $10 \%$ (23) of the study sample to test the clarity, feasibility of the questions and to determine the time needed to fill-in questions. Nursing staff who shared in the pilot study were excluded from the total sample to appraise the clarity, feasibility and applicability of the tools and necessary modifications were done based on their responses.

\section{Ethical consideration:}

Formal approval was be obtained from the research ethics committee of Faculty of Nursing , Mansoura University(Ref:208). An official permission to conduct the study obtained from the responsible administrator of the hospital, the participation was voluntary, and confidentiality and anonymity of the subject were assured through coding of all data. Privacy of the study sample was be assured. The results will be used as a component of necessary research. As well as it will be used for future publication and education. 
1Eman Saad El Desoky' et. al.

\section{Data collection:}

The researcher collected data through interviewing and distributing questionnaire to each subject in the study during work hours in morning and afternoon shifts. The aim of the study and how to fill tool was explained by the researcher. Give 20 minutes to fill the questionnaire sheets. The number of collected questionnaire sheets from nursing staff per day ranged from 7-8 sheets. The researcher went to hospital two days per week. Data collection took three months from beginning of February to end of April 2020.

\section{Statistical analysis:}

After the data collected it was revised, tabulated, coded and statistically analyzed using SPSS software (Statistical Package for the Social

Table (1): Demographic data of the studied nursing staff at Kafr El Sheikh University Hospital $(\mathrm{N}=185)$.

\begin{tabular}{|c|c|c|}
\hline Characteristics & No & $\%$ \\
\hline \multicolumn{3}{|l|}{ Age } \\
\hline $20-25$ & 128 & 69.2 \\
\hline - $\quad 26-30$ & 54 & 29.2 \\
\hline$>30$ & 3 & 1.6 \\
\hline Mean \pm SD & \multicolumn{2}{|c|}{$25.13 \pm 2.89$} \\
\hline \multicolumn{3}{|l|}{ Gender } \\
\hline - Male & 29 & 15.7 \\
\hline - Female & 156 & 84.3 \\
\hline \multicolumn{3}{|l|}{ Marital status } \\
\hline - $\quad$ Single & 67 & 36.2 \\
\hline - Married & 115 & 62.2 \\
\hline - Divorced & 2 & 1.1 \\
\hline - Widowed & 1 & 0.5 \\
\hline \multicolumn{3}{|l|}{ Level of education } \\
\hline - $\quad$ Technical degree & 94 & 50.8 \\
\hline Bachelor degree & 89 & 48.1 \\
\hline Master degree & 2 & 1.1 \\
\hline \multicolumn{3}{|l|}{ Job title } \\
\hline - Technical nurse & 94 & 50.8 \\
\hline - $\quad$ Nurse specialist & 68 & 36.8 \\
\hline - Head nurse & 17 & 9.2 \\
\hline Nursing supervisor & 5 & 2.7 \\
\hline Nursing director & 1 & 0.5 \\
\hline \multicolumn{3}{|l|}{ Experience years } \\
\hline$-1-5$ & 176 & 95.1 \\
\hline - $6-10$ & 7 & 3.8 \\
\hline - $>10$ & 2 & 1.1 \\
\hline Mean \pm SD & \multicolumn{2}{|c|}{$3.09 \pm 2.56$} \\
\hline
\end{tabular}

Sciences, version 22). Descriptive statistics were applied in the form off mean and standard deviation for quantitative variable. Descriptive statistics were applied in the form frequency $\&$ percentages for qualitative variable, comparison between two groups and more was done using Chisquare test (X2). T-test was utilized to compare among means of two groups of parametric data of independent samples. $F$ value of ANOVA test was calculated to compare among more than two means of parametric data. Pearson correlational coefficient was calculated between variables. Statistical significance level value was considered when $\mathrm{p}$ - value $<0.05$ and a highly

Results: 
Table (1): Demographic data of the studied nursing staff. The table revealed that, total studied sample were(185) nursing staff, the majority of them $(69.2 \%)$ were in age group 20 25 years old, Most of them (84.3\%) were female, $(62.2 \%)$ of nursing staff

Table (2): Mean score of organizational culture domains as perceived by nursing staff at Kafr El Sheikh University Hospital (N=185).

\begin{tabular}{|l|c|c|c|c|c|}
\hline $\begin{array}{l}\text { Organizational culture } \\
\text { domains }\end{array}$ & $\begin{array}{l}\text { No. of } \\
\text { items }\end{array}$ & $\begin{array}{c}\text { (Min- } \\
\text { Max) }\end{array}$ & Mean \pm SD & $\begin{array}{c}\text { Mean \% of } \\
\text { total score }\end{array}$ & Ranking \\
\hline $\begin{array}{l}\text { A-Dominant } \\
\text { characteristics }\end{array}$ & 4 & $(4-20)$ & $15.49 \pm 2.03$ & $77.2 \%$ & 3 \\
\hline $\begin{array}{l}\text { B-Organizational } \\
\text { leadership }\end{array}$ & 4 & $(4-20)$ & $15.12 \pm 2.00$ & $75.6 \%$ & 4 \\
\hline $\begin{array}{l}\text { C-Management of } \\
\text { employees }\end{array}$ & 4 & $(4-20)$ & $15.00 \pm 2.24$ & $75.0 \%$ & 6 \\
\hline D-Organization glue & 4 & $(4-20)$ & $15.52 \pm 2.27$ & $77.6 \%$ & 2 \\
\hline E-Strategic emphases & 4 & $(4-20)$ & $15.05 \pm 2.36$ & $75.2 \%$ & 5 \\
\hline F-Criteria of success & 4 & $(4-20)$ & $16.05 \pm 2.26$ & $80.2 \%$ & 1 \\
\hline
\end{tabular}

Table (2): Mean score of organizational culture domains as perceived by nursing staff. The table show the mean score of criteria of success was the highest mean percent $(80.2 \%)$ with mean score (16.05 2.26$)$ followed by organizational glue domain with mean percent $(77.6 \%)$ and mean score (15.52 \pm 2.27$)$, while the lowest

Figure (1): Organizational culture levels among the studied nursing staff at Kafr El Sheikh University Hospital $(\mathrm{n}=185)$.

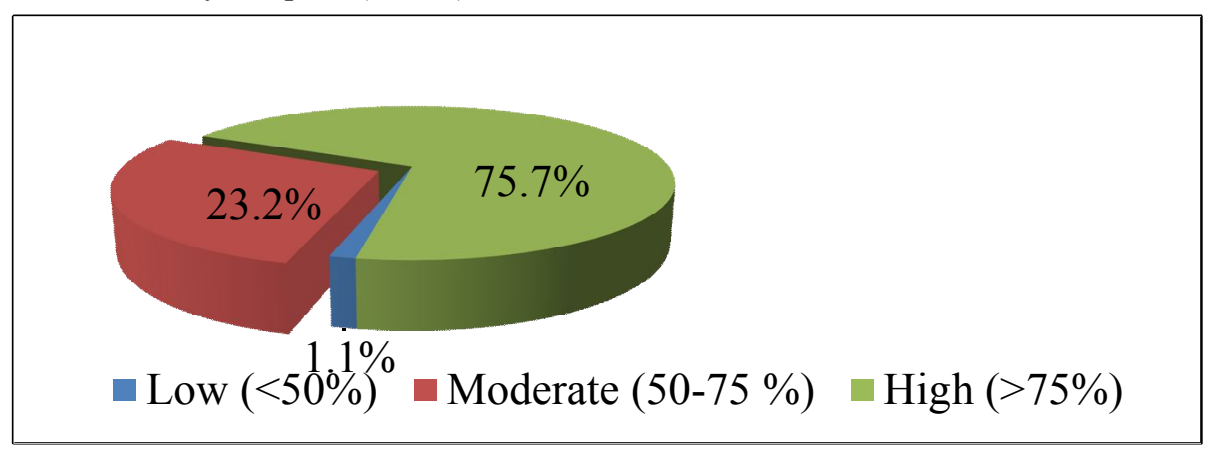

Figure(1): Showed Organizational culture levels among the studied nursing staff at kafr el sheikh university hospital.(75.7\%) of studied sample had high level of organizational culture and $(23.2 \%)$ of them have moderate level of organizational culture, while $(1.1 \%)$ of them had low level perception of organizational culture. married, $(50.8 \%)$ half of them were technical degree of education and worked as staff nurse. High percent $(95.1 \%)$ of nursing staff had (1-5) years of professional experience with mean score $(3.09 \pm 2.56)$.

perception was for strategic emphases with mean percent $(75.2 \%)$ and mean score (15.05 \pm 2.36$)$, followed by management of employees with mean percent $(75.0 \%)$ and mean score (15.00 \pm 2.24$) \quad$ perception of organizational culture domains among nursing staff 
IEman Saad El Desoky' et. al.

Table (3): Mean score of nursing staff perception regarding individual innovation at Kafr El Sheikh University Hospital ( $\mathrm{N}=185)$.

\begin{tabular}{|l|c|c|c|c|c|}
\hline $\begin{array}{c}\text { Individual innovation } \\
\text { domains }\end{array}$ & $\begin{array}{c}\text { No. of } \\
\text { items }\end{array}$ & $\begin{array}{c}\text { (Min- } \\
\text { Max) }\end{array}$ & Mean \pm SD & $\begin{array}{c}\text { Mean \% of } \\
\text { total score }\end{array}$ & Rank \\
\hline $\begin{array}{c}\text { A-Openness to } \\
\text { experience }\end{array}$ & 5 & $(5-25)$ & $20.24 \pm 2.33$ & $80.96 \%$ & 2 \\
\hline $\begin{array}{c}\text { B-Prime mover } \\
\text { originator }\end{array}$ & 5 & $(5-25)$ & $19.43 \pm 2.31$ & $77.72 \%$ & 3 \\
\hline C- Readiness to change & 8 & $(8-40)$ & $24.47 \pm 6.77$ & $61.18 \%$ & 4 \\
\hline D-Risk Taking domain & 2 & $(2-10)$ & $8.26 \pm 3.17$ & $82.6 \%$ & 1 \\
\hline
\end{tabular}

Table (3): Mean score of nursing staff perception regarding individual innovation at Kafr El Sheikh University Hospital. This table demonstrated that risk taking domain, perceived as being the highest mean percent $(82.6 \%)$ among nursing staff with mean score of $(8.26 \pm 3.17)$ followed by openness to experience $(80.96 \%)$ with mean score of (20.24 \pm 2.33$)$. whereas, the lowest perception was for readiness to change with mean percent $(61.18 \%)$ and mean score $(24.47 \pm 6.77)$ perception of individual innovation domains.

Figure (2): Individual innovation levels as perceived by nursing staff at Kafr El Sheikh University Hospital ( $\mathrm{N}=185)$.

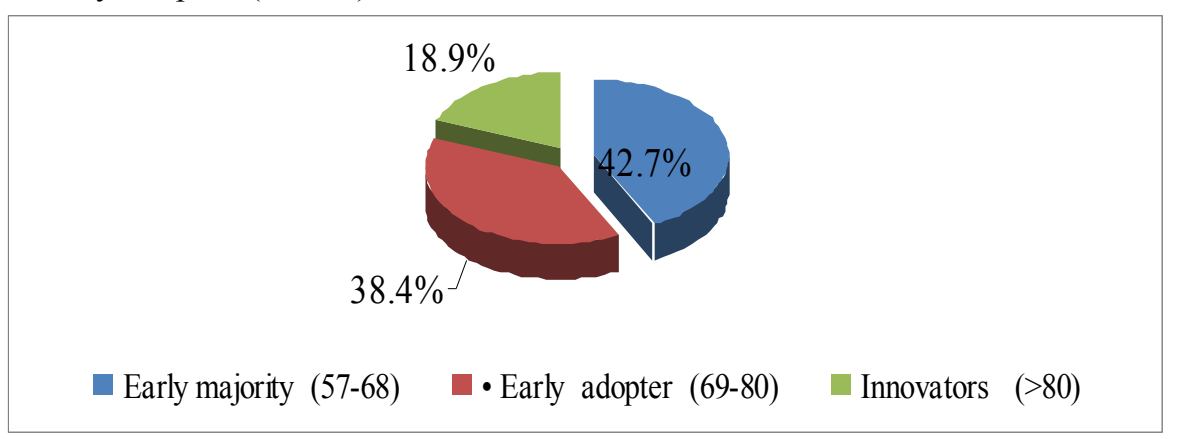

Figure (2): Revealed levels of Individual innovation as perceived by nursing staff at Kafr El Sheikh University Hospital. $(42.7 \%)$ of studied sample were early

Table (4): Individual innovation levels as perceived by nursing staff at Kafr El Sheikh University Hospital $\{$ In general $\}(\mathrm{N}=185)$.

\begin{tabular}{|ll|c|c|}
\hline Individual innovation levels & $\mathbf{N}$ & $\mathbf{\%}$ \\
\hline$\bullet \quad$ Low in innovation $(<64)$ & 42 & 22.7 \\
\hline$\bullet \quad$ Moderate in innovation $(64-68)$ & 32 & 17.3 \\
\hline$\bullet$ & Highly innovative $(>68)$ & 111 & 60 \\
\hline
\end{tabular}

majority and (38.4\%) of them early adopter, while (18.9)\% of them were innovators. 
Table (4): Showed levels of Individual innovation \{In general\} as perceived by nursing staff at Kafr El Sheikh University Hospital. (60\%) of

Table (5): Mean score of Nursing staff perception regarding work engagement at Kafr El Sheikh University Hospital ( $\mathrm{N}=185)$.

\begin{tabular}{|l|c|c|c|c|c|}
\hline $\begin{array}{c}\text { Work engagement } \\
\text { domains }\end{array}$ & $\begin{array}{l}\text { No. of } \\
\text { item }\end{array}$ & $\begin{array}{c}\text { (Min- } \\
\text { Max) }\end{array}$ & Mean \pm SD & $\begin{array}{c}\text { Mean\% of total } \\
\text { score }\end{array}$ & $\begin{array}{c}\text { Ran } \\
\text { king }\end{array}$ \\
\hline A -Vigor & 6 & $(0-24)$ & $17.31 \pm 3.58$ & $72.1 \%$ & 3 \\
\hline B-Deduction & 5 & $(0-20)$ & $15.38 \pm 3.20$ & $76.9 \%$ & 1 \\
\hline C-Absorption & 6 & $(0-24)$ & $17.65 \pm 4.41$ & $73.5 \%$ & 2 \\
\hline
\end{tabular}
engagement domains as perceived by nursing staff. The table illustrated that dedication, perceived as being the highest mean percent $(76.9 \%)$ among nursing staff with mean score of $(15.38 \pm 3.20)$ followed by absorption

Figure (3): Work engagement levels as perceived by nursing staff at Kafr El Sheikh

University Hospital $(\mathrm{N}=185)$.

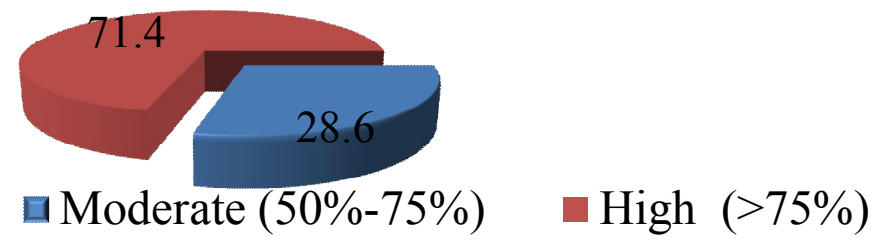

Figure (3): Demonstrated levels of work engagement among the studied nursing staff at Kafr El Sheikh

University Hospital. (71.4\%) of studied studied sample are highly innovative and $(22.7 \%)$ of them low innovation, while $(17.3 \%)$ of them are moderate innovation.

(17.65 \pm 4.41$)$. On the other hand, vigor perceived as the lowest mean percent $(72.1 \%)$ with mean score $(17.31 \pm 3.58)$ perception of work engagement domains among nursing staff sample had high level of work engagement, while $(28.6 \%)$ of them had moderate level of work engagement. 
IEman Saad El Desoky' et. al.

Table (6): Correlation coefficient between domains of organizational culture, individual innovation and work engagement as perceived by nursing staff at Kafr El Sheikh University Hospital ( $\mathrm{N}=185)$.

\begin{tabular}{|c|c|c|c|c|c|c|c|c|}
\hline \multirow{3}{*}{ Variables } & \multicolumn{8}{|c|}{ work engagement scores among the studied nursing staff $(n=185)$. } \\
\hline & \multicolumn{2}{|c|}{ A-vigor } & \multicolumn{2}{|c|}{ B-deduction } & \multicolumn{2}{|c|}{ C-Absorption } & \multicolumn{2}{|c|}{$\begin{array}{c}\text { Total work } \\
\text { engagement scores }\end{array}$} \\
\hline & $\mathbf{R}$ & $\mathbf{P}$ & $\mathbf{R}$ & $\mathbf{P}$ & $\overline{\mathbf{R}}$ & $\mathbf{P}$ & $\mathbf{r}$ & $\mathbf{P}$ \\
\hline $\begin{array}{l}\text { A-Dominant } \\
\text { characteristics }\end{array}$ & 0.351 & $0.000 * *$ & 0.264 & $0.000 * *$ & 0.407 & $0.000 * *$ & 0.436 & $0.000 \% *$ \\
\hline $\begin{array}{l}\text { B-Organizational } \\
\text { leadership }\end{array}$ & 0.226 & $0.002 * *$ & 0.188 & $0.011 *$ & 0.289 & $0.000 * *$ & 0.300 & $0.000 * *$ \\
\hline $\begin{array}{l}\text { C-Management of } \\
\text { employees }\end{array}$ & 0.332 & $0.000 * *$ & 0.215 & $0.003 * *$ & 0.312 & $0.000 * *$ & 0.364 & $0.000 * *$ \\
\hline D-Organization glue & 0.197 & $0.007 * *$ & 0.187 & $0.011^{*}$ & 0.250 & $0.001 * *$ & 0.269 & $0.000 * *$ \\
\hline E-Strategic emphases & 0.223 & $0.002 * *$ & 0.199 & $0.007 * *$ & 0.246 & $0.001 * *$ & 0.282 & $0.000 * *$ \\
\hline F-Criteria of success & 0.264 & $0.000 * *$ & 0.256 & $0.000 * *$ & 0.155 & $0.035 *$ & 0.274 & $0.000 *$ \\
\hline $\begin{array}{l}\text { Total organizational } \\
\text { culture }\end{array}$ & 0.327 & $0.000 * *$ & 0.270 & $0.000 * *$ & 0.339 & $0.000 * *$ & 0.395 & $0.000 * *$ \\
\hline $\begin{array}{l}\text { A-Openness to } \\
\text { experience }\end{array}$ & 0.314 & $0.000 * *$ & 0.370 & $0.000 * *$ & 0.251 & $0.001 * *$ & 0.382 & $0.000 * *$ \\
\hline $\begin{array}{l}\text { B-Prime mover } \\
\text { originator }\end{array}$ & 0.417 & $0.000 * *$ & 0.326 & $0.000 * *$ & 0.279 & $0.000 * *$ & 0.421 & $0.000 * *$ \\
\hline $\begin{array}{l}\text { C-Readiness to } \\
\text { change }\end{array}$ & 0.143 & 0.052 & 0.131 & 0.077 & 0.061 & 0.413 & 0.134 & 0.069 \\
\hline D-Risk taking & $0 . \overline{0} 2$ & 0.567 & 0.059 & 0.421 & 0.057 & 0.440 & 0.032 & 0.661 \\
\hline $\begin{array}{l}\text { Total individual } \\
\text { innovation }\end{array}$ & 0.265 & $0.000 * *$ & 0.282 & $0.000 * *$ & 0.191 & $0.009 * *$ & 0.301 & $0.000 * *$ \\
\hline
\end{tabular}

\section{** Highly statistically significant} $(\mathbf{P} \leq \mathbf{0 . 0 1})$

Table (6): Demonstrated the correlations coefficient between domains of organizational culture and individual innovation with work engagement as perceived by nursing staff. Statistical

significant correlations were found between all domains of organizational culture and individual innovation with all domains of work engagement at Kafr El Sheikh University Hospital (P<0.01) expects (readiness to change and risk taking domains).

Figure (4): Correlation between organizational culture and work engagement as perceived by nursing staff at Kafr EI Sheikh University Hospital (N=185).

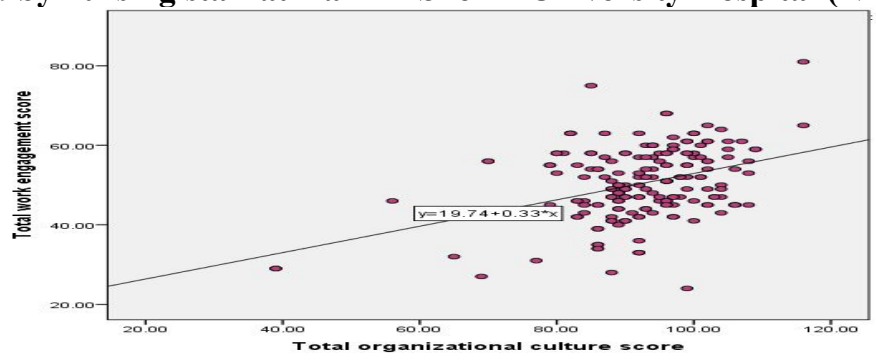

Figure (4): Demonstrated that there was statistically significant positive correlation between organizational culture and work engagement as perceived by nursing staff at Kafr El Sheikh University Hospital. 
Figure (5): Correlation between individual innovation and work engagement as perceived by nursing staff at Kafr El Sheikh University Hospital ( $\mathrm{N}=185)$.

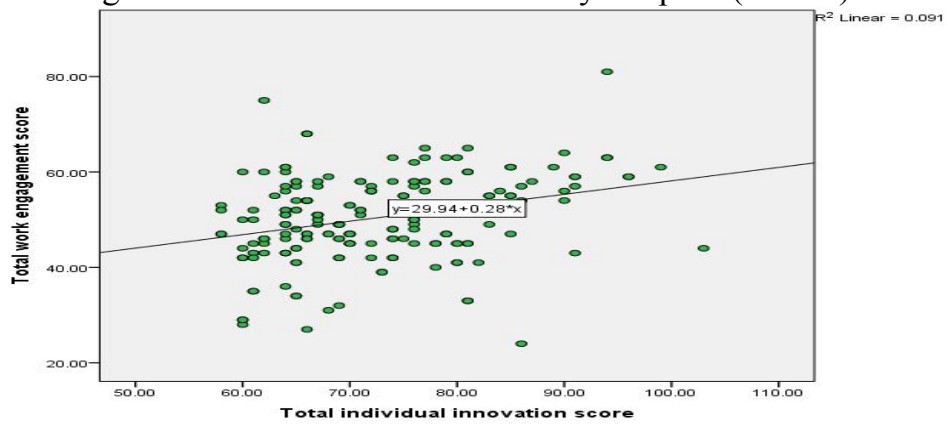

Figure (5): Demonstrated that there was statistically significant positive correlation between individual innovation and work engagement as perceived by nursing staff at Kafr El Sheikh University Hospital.

\section{Discussion}

Organizational culture has the potential to improve organizational performance, job satisfaction and enhance the sense of certainty about problem solving. In the rapid changing environment, organizations are facing more challenges and they need to encourage innovative behaviors to generate and deliver their services to stay competitive and lead the change process itself in order to achieve their task successfully, organizations render support to their staffs to innovate their manner, techniques and processes and to be more engaged in their work .Decuypere, Audenaert, \&Decramer, (2020).

Regarding to the variables investigated in the present study. The present study sought nursing staff perception of organizational culture domains, the result showed that criteria of success had the highest mean score which came first in ranking followed by organizational glue domain. This may be due to the hospital have strong culture is one of the characteristics of a healthy organization and is set largely by leaders in the hospital. The strong culture build group cohesiveness that imply a high level of integration and congruence of values and believes throughout an organization, which lead to effective dealing with problems of internal integration and external adaptation. Also, the hospital as a health care institution aim to achieve predetermined goals successfully, determine the best way for doing functions in the hospital, provide best healthcare services, save available resources and increase quality of services. Furthermore, this may be attributed to the presence of clear policies and rules within the hospitals which enhance nurses' loyalty and commitment.

The result was similar to Globocnik, Rauter,\& Baumgartner, (2020)who analyzed six dimensions of organizational culture assessment instrument using the competing values framework and reported that the highest mean score for the culture was criteria for success dimension followed by organizational glue because of ongoing clear communication up and down the organizational hierarchy that motivates nurses for humanistic-encouraging and 
1Eman Saad El Desoky' et. al.

affiliative norms which are necessary for the organizational survival.

As well, Alhiddi, Osborne, \&Anyigor, (2019) who conducted study about organizational culture and success criteria among nurses at Newcastle and showed that criteria for success and organizational glue as perceived by organizational staff may keeping its resources and act as improve quality of services that provided for patient. Nurses emphasis is placed on the examination of organization outcomes and the factors that influence cultural domains. Stakeholder management, nurses and corporate culture are critical areas that decide an organization's success and clear rules and regulations which promote nurses' satisfaction and commitment.

On the other hand, this study result was dissimilar to Brown, PazAparicio, \& Revilla, (2019) who studied leader's communication style, and organizational culture of nurses in Zanjan Hospitals and reported that there was no statistical significant difference related to criteria for success and organizational glue as organizational members may waste its resources and act against it which in turn decreases quality of services.

While, the present study showed that the lowest mean score was for strategic emphases, followed by management of employees regarding perception of organizational culture domains among nursing staff. This may be attributed to that staff nurses are not allowed to involve in strategic planning as strategic planning limited for management level, their point of view are not considered in future planning by hospital management, and hospital mostly not consider strategic emphases implanting in nurses.
This result was matched with ElKordy, (2013) who conduct study about transformational leadership and organizational culture as predictors of nurses attitudinal outcomes and stated the lowest percent was related to strategic emphases, followed by management of employees regarding organizational culture domains as improper strategic map and nurses are not involved in planning.

However, this result was contradict with Mac-Rizzo, (2020) who stated that strategic emphases had the highest mean percent followed by management of employee as it enhances planning the future, mapping strategic plans, improves nurses' productivity, measures clients' rights, preferences, and guides healthcare organizations.

Furthermore, Aalaee \&Pourtaheri, (2012) who studied the effect of domains of organizational culture on knowledge management in educational-treatment hospitals of Kerman and mentioned that strategic emphases and management of employee had the most essential mean scores that viewed in goals clarification, effective management of organizational resources, goals consideration, healthcare organizational growth, enhances healthcare organizational management to make a prediction of changes priorities, and to perform organizational functions successfully.

In relation to levels of organizational culture among nursing staff, the present study showed that the majority of nursing staff had the highest level of perception of organizational culture. This may be due to that the hospital is a very dynamic and entrepreneurial place that inspires nursing staff to work as a team that promote hard work, create trust work environment, mutual respect among staff 
and improve their willing to take risks. In so doing, it helps their staff to meet the organization's set goals.

Also, most probably this result may be due to that Kafr el Sheikh University Hospital was characterized by adequate staffing levels, flexible scheduling for their nursing staff, have sufficient and strong support from supervisors, have sufficient and strong recognition for excellence practice. Furthermore, nursing staff are the major assets of the hospital with different specializations, educational qualifications and work experiences that contribute effectively within successful organization. All of these contributed to strong organizational culture among nursing staff and they have trust about their effective role in the hospital.

This is consistent with Yavuz, (2010)who examined the effects of culture on organizational commitment among nurses at Konya and reported that nurses had high level of perception of organizational culture because of culture enhances nurse's performance and creates a more active workplace environment and promote better communication and understanding towards achieving a common goal.

Also, congruent with Kamel , \&Aref, (2017) who conducted study about organizational culture and its relation to innovative work behavior at critical care units among staff nurses at Benha University Hospital and reported that more than half of staff nurses had high perception level regarding organizational culture as leaders in this organization improve the working conditions of the staff nurses and make them able to work with less strain and it would be more compatible and flexible that help them to adapt with their culture.
On the other hand, the present result was in disagreement with Sutter, (2020) who studied organizational culture among nurses in United States Military Branches and stated as general, staff had low level of perception for culture because of rigid rules and policies that used for dealing with their staff's.

Regarding individual innovation of nursing staff, the result of present study demonstrated that risk taking domain perceived as being the highest mean score which came first in ranking followed by openness to experience among nursing staff. This may be due to clear values, vision and objectives are important segments in shaping risk taking abilities among nursing staff. Also supervisors recognize support their innovative efforts, provide them with the resources needed to innovate and consult them in the decision making process to enhance risk taking among nurses. Work environment where risk taking is encouraged and valued throughout the whole hospital , nursing staffs' innovative self-efficacy are enhanced.

Also, This may be due to nursing staff considered that their work is a part of their life and good relationship with their colleague's that build high commitment to their work that improve openness to experience and good support that affect positively on personality traits of nurses.

On the same line with result Azevedo, \& Shane,(2019)who conducted study about cultural intelligence to improve innovative work behavior and resilience among nurses and confirmed that predicting individual innovation at work in professional conduct stems more from personality factors or personal creativity than from the perception of encouragement 
received or the experience of the social environment that affect positively on them to take risk and improve their openness to experience.

Furthermore, the present finding was matched with Waheed, Miao, Waheed, Ahmad, \&Majeed, (2019) who examined how organizational innovation, and innovative climate affect the innovation performance among nurses at Pakistan and stated that organizations are seeking to innovation order to do that, they need to bet on their human resources potential and establish a favorable climate for the emergence of creativity as a means of innovation through take risk and openness to experience that are most essential domain in individual innovation. Therefore, it is necessary to promote trust, which will trigger commitment in employees, who will feel more connected to the in agreement with organization.

On the other side Sarmad, \& Bashir, (2016) who conducted study about impact of nurses' innovation on patients' satisfaction showed that openness to experience domain and risk taking act as highest mean score among nurses. In general maintenance for nurse's openness to experience and risk taking found that affect patient's satisfaction superior.

Meanwhile, the present study demonstrated that readiness to change domain have the lowest mean scores of individual innovation. From the researcher point of view this result could be related to inadequate resources, vague information about change, and lack of staff training and development for change process and management. Therefore, nurses may be less motivated to participate in any change program. All of these may affect their willingness to change.

This findings was supported by Celik, (2013) who found domains studied in individual innovation among nurses that the highest mean score was openness to experiences dimension followed by opinion-leading then risktaking while the lowest mean score readiness to change dimension.

Moreover,Kalman, Bozbayindir, (2017) who examined dispositional resistance, change-specific resistance and change-related information among nurses found lower dispositional readiness to change among study participants at Turkey.

Regarding individual innovation levels, the finding of the study show that more than half of nursing staff were early adapter and innovator, and as general had highly innovative level. Early adopter and innovator levels of innovation mean a person who embraces new technology before most other people do and innovator is someone who introduces changes and new ideas. This is due to the innovation come up with new ideas primarily depends on individuals and partly on the management of an organization. Firstly, the ability to create innovative solutions is dependent on the knowledge, and even more on the experience of individuals to apply the knowledge to solve the novel problem and generating new ideas.

Secondly,managementand nursing leaders supported their staff in openly presenting and implementing their ideas and practice, so that they would feel that they were important in the organization and would feel empowered that affect positively their perception to their creative thinking.

Consistent with the present study Stoffers, Neessen \& Dorp, (2015) 
examined organizational culture and innovative work behavior among nurses at Netherlands and confirmed that the nurses valued innovative work behavior higher in the preferred status than in the current status. As well, in this same respect, Ikiz, \&Asici, (2017)who found that their staff were generally in the group of early adopters in terms of individual innovativeness.

This result was in contrast with El-Aliem, \&Hamouda, (2020). Who showed that less than half of studied nurses had moderate level of total innovation .Meanwhile, more than one third of them had low level, as weak personal skills, poor self-awareness, fear to failure and organizational culture blame.

As well, Kurtipek, \&Gungor, (2019) who conducted study about individual innovation: a research on manager nurses and reported that according to total score, the participants are mild innovative. Furthermore, Yang, Zhou, Wang, Lin, \&Luo, (2019) who examined innovative behavior among Chinese nurses and showed that the level of innovative behavior among head nurses were in the middle level.

Regarding work engagement of nursing staff, the finding of the study indicated that deduction as work engagement domain had the highest mean scores and was ranked as a first domain of work engagement followed by absorption and vigor domain had the lowest means scores. This may be due to strong organizational support preserves their nurses by making a safe environment and suitable for work, helping them in solving of their problems and making decisions. So, nurses feel with dedication, high emotion and high feeling of enthusiastic and pride toward their job.
The study finding confirmed by Kindipan,(2017) who studied about work engagement and intent to stay among staff nurses in acute care hospitals and found that new graduate nurses experienced dedication as the highest work engagement factor followed by absorption and vigor.

Consistent with the study result Støren, (2017) approved that dedication and absorption dimension was positively associated with self-transcendence, the ability to find meaning in life by being directed to word something or someone other than one self.

This result was consistent with Listau, (2017) who conducted study about work engagement at Scandinavian, and stated that vigor domain were the lowest score in work engagement among nurses as the direct supervisor for head nurses that had a strong direct positively or negatively effect on vigor character by using encouragement and punishment that effect on level of energy that staff put on work.

Inconsistent with the result, Seada, (2017) who studied role stress and work engagement among nurses in a selected hospital in Cairo reported that absorption domain had the highest mean score followed by vigor among staff nurses. Furthermore, this result was dissimilar with Aboshaiqah, Hamadi, Salem, \&Zakari, (2016)who examined the work engagement of nurses in multiple hospital sectors in Saudi Arabia, revealed that nurses had high mean scores of vigor followed by dedication and then absorption in both magnet and non- magnet hospitals.

Furthermore, incompatible with the result Hisel, (2020) who measuring work engagement in a multigenerational nursing workforce at Portuguese and Spanish, stated that vigor character of 
work engagement had the highest mean score followed by deduction then absorption.

The finding of study revealed that more than two third of nursing staff have high level of work engagement. Nursing staff at Kafr El Sheikh University Hospital feel more comfortable in dealing with their colleague's, and their physicians, feel autonomy in work and the atmosphere at this hospital help nursing staff every day to learn new skills and motivates them to perform at the highest level.

Vera,Martínez,Lorente,\&Cha

mbe, (2015)found that strong supervisor support, social support and job autonomy lead to high work engagement among Portuguese nurses during study about job autonomy and work engagement. Also Radwan,(2019) who examined organizational support and work engagement among head nurses at Main Mansoura University Hospital found that the majority of head nurses had high level of work engagement.

However, this result was inconsistent with Rothmann, (2017) who studied employee engagement among Japanese people suggested that extremely low scores of the Japanese Utrecht Work Engagement Scale (UWES) do not necessarily indicate low work engagement.

Regarding correlation between study variables as perceived by nursing staff, the finding of the study revealed that there was highly statistically significant positive correlation between organizational culture and individual innovation with work engagement. This may be due to hospital provide support to their nursing staff by providing a safe atmosphere that appropriate for labor, helping them in making decisions and problem solving that allow and stimulate individual innovation so they feel with satisfaction and engagement in work.

Moreover, the presence of good culture in the hospital and presence of degree of freedom that allow nursing staff to take risk and presence of clear communication improve nursing staff commitment and capability for innovation. Thus, benefiting the organizations overall innovation performance and improve work engagement and retention for nursing staff. Also, presence of clear policies and rules within the hospitals allow the staff to engage in behaviors that could lead to positive consequences such as satisfaction, commitment.

Also, nature of work field that nursing staff worked in and performing their procedures in different way that could taking risk for improving quality of care for patient and presence environment promote nursing staff to take decisions that positively affect the system toward organization.

This result was agreed with Lara, (2019) who studied the effects of nurses' perception of their personalorganizational culture fit, and individual innovation on employee engagement, found that positive correlation between personalorganizational culture fit, and individual innovation on employee engagement. Additionally,Sánchez $\square$ Báez,Fernández - Serrano, \& Romero, (2020) who examined organizational culture and innovation in small hospital at in Paraguay and assumed that positive correlation between Organizational Culture and Individual Innovation.

Moreover, Naidoo, \& Martins, (2014) who conducted study about relationship between organizational culture and work engagement, reported that all the dimensions of organizational 
culture correlate positively with work engagement dimensions. Also, Lin, \& Lee, (2017) who studied influence of organizational learning on employees' innovative behavior and work engagement conducted that work engagement has a significantly positive influence on employees' innovative behavior.

But, this result was inconsistent with Brenyah, \&Obuobisa-Darko, (2017) who studied about organizational culture and employee engagement, assumed that the relationship between role culture and employee engagement is not significant.

Conclusion:

Based on the study findings, it was concluded that nursing staff at Kafr El Sheikh Hospital had high level of perception about organizational culture, highly innovative level and had high level of work engagement. This means nursing staff that highly perceived of organizational culture and highly innovative are highly engaged at work.

\section{Recommendations:}

\section{Based on the findings recommended} to:

Incorporate culture in the hospital policy by giving the chance to every staff in the hospital to participate in decision making.

Nursing manager should sustain a culture of communication and utilization of shared decision making which empower nursing staff to participate in decisions that affect their work processes.

Provide training programs about the importance of creativity for enhancing hospital ability and efficiency, and how mangers can use their problem solving styles effectively.

Respond positively to the innovative efforts by provide nursing staff the time and resources to carry out innovative efforts.

Increase nursing staff readiness to change through communicating the objectives, methods and process of introducing new changes and technologies.

Develop a mentorship program where more experienced nursing staff act as models and mentors to the new nursing staff in the profession to empower and motivate them to engage in their work.

Making a trust relationship between nursing administration and staff nurses and provide them with needed support so they may be more engaged with their organization.

\section{References}

Abd-Elkawey, H., \& Sleem, W. (2015). Factors Affecting Nurses' Readiness for Change in Health Care Organizations. International Journal of Advanced Research, 3(11), 1330-1343.

Aboshaiqah, A., Hamadi, H., Salem, O., \& Zakari, N. (2016). The Work Engagement of Nurses in Multiple Hospital Sectors in Saudi Arabia: A Comparative Study. Journal of nursing management, 24 (4), 540-548.

Abou Hashish, E., Abdel All, N., \& Mousa,A.(2018).Nurses'erception of Psychological Empowerment and its Relationship to Work Engagement and Job Insecurity. Journal of Nursing Education and Practice, 8(9), 36-44.

Agresti, A. (2018). An Introduction to Categorical Data Analysis. John Wiley\&Sons, $3^{\text {rd }}$ Edition.https://w ww.wiley.com/enus/An+Introduc tion+to+Categorical+Data+Anal ysis\%2C+3rd+Edition-p$\mathbf{9 7 8 1 1 1 9 4 0 5 2 8 3}$ 
Alhiddi, A., Osborne, A. N., \& Anyigor, K. T. (2019).

Organizational culture and success criteria among nurses in hospital. Periodica Polytechnica Architecture scientific journal, 50(2), 148-154.

Anderson, N., Potočnik, K., \& Zhou, J. (2014): Innovation and Creativity in Organizations: A state-of-The-Science Review, Prospective Commentary, and Guiding Framework. Journal of Management, 40(5), 1297-1333.

Andrew, A. (2017). Relationship between Employee Readiness for Organizational Change and Employee Performance. Journal for Studies in Management and Planning, 3(1), 23-35.

Azevedo, A., \& Shane, M. (2019). A New Training Program in Developing Cultural Intelligence can also Improve Innovative Work Behavior and Resilience among Nurses: A longitudinal pilot study of graduate students and professional employees. The International Journal of Management Education, 17(3), 100303.

Bakker, A., Petrou, P., Op den Kamp, E., \& Tims, M. (2020). Proactive Vitality Management, Work Engagement, and Creativity: The Role of Goal Orientation. Journals of the International Association of Applied Psychology, 69(2), 351-378.

Brenyah, R., \& Obuobisa-Darko, T. (2017). Organizational Culture and Employee Engagement within the Ghanaian Public Sector. Review of Public Administration and Management journal, 5(3), 1-7.
Brown, O., Paz-Aparicio, C., \& Revilla, A. (2019). Leader's Communication Style, and Organizational Culture: A study of Employee Perceptions in Peru. Leadership\&Organization Development Journal, 40(2).

Celik, K. (2013). The Relationship between Individual Innovativeness and Self-Efficacy Levels of Nurses. International Journal of Scientific Research in Education, 6(1), 56-67.

Christensen,T.,Lagreid,P.,Rovik, K. (2020). Organization Theory and ThePublicSector:Instrument, Cultur eandMyth, ilableathttps://www.routledge.com

Decuypere, A., Audenaert, M., \& Decramer, A. (2020). Leader Mindfulness: Well-Being Throughout the Organization. The Palgrave Handbook of Workplace Well-Being, 1-28 https://biblio.ugent.be/publicatio n/8659907.

El-Aliem, S., \& Hamouda, G. (2020). Relationship between Organizational Support and Nurses' Perceived Citizenship and Innovation. Journal of Nursing and Health Science, 9 (1), 1-10.

Elewa, A., \& Banan, E. (2019). Organizational culture, organizational trust and workplace bullying among staff nurses at public and private hospitals. International Journal of Nursing Didactics, 9(4), 10-20.

Elgamal,H.(2018):Relationship between organizational culture and organizational Communication as perceived by nursing staff. Unpublished master Thesis. Faculty of nursing: Alexandria University, 83-86. 
EIKordy, M. (2013). Transformational Leadership and Organizational Culture as Predictors of Employee's Attitudinal Outcomes among Nurses. Business Management Dynamics Journal, 3(5), 15.

El-Sayed,F.,Seada,A.,\&El-uindy,H. (2017). Factors associated with Nurses'Readinessfor rganizational Change at Beni Sueif University Hospital. Egyptian Nursing Journal, 14(2), 141.

Globocnik, D., Rauter, R., \& Baumgartner, R. (2020). Synergy or Conflict? The Relationships among Organizational Culture, Sustainability-related Innovation Performance, and Nurses Innovation Performance. International Journal of Innovation Management, 24(01), 12-15.

Greer, A., Selladurai, R., Pfeifle, A., Selladurai, R., \& Hobson, C. (2020).Effective Teamwork and Healthcare Delivery Outcomes. In Evaluating Challenges and Opportunities for Healthcare Reform, 77-99.

Hisel,M.(2020).Measuring work engagement in a multigenerational nursing workforce.Journal of Nursing Management, 28(2), 294305.

Hurt, H., Joseph, K., \& Cook, C. (2013):ScalesforThe Measurement of Innovativeness. Human Communication Research Journal, 4(1), 58-65.

Ikiz, F., \& Asici, E. (2017). The Relationship between Individual Innovativeness and Psychological Well-Being: The Example of Turkish Counselor Trainees. International Journalof Progressive Education, 13(1), 52-63.
Kalman,M., Bozbayindir,F. (2017). An Investigation of Dispositional Resistance, Change-specific esistance and Change-related InformationamongNurses.ultidisci plinary Journal of Educational Research,7(2), 125-155.

Kamel, F., \& Aref, M. (2017). Staff Nurses Perception toward Organizational Culture and its relation to Innovative Work Behavior at Critical care units. American Journal of Nursing, 6(3), 251-260.

Kerns,C.(2020).Managing

Organizational Culture: A Practice-Oriented Framework. International Leadership Journal, 12(1)115-170.

Kindipan, I. (2017). The Role of Leader Empowering Behaviors on Work Engagement and Intent to Stay among Staff Nurses in Acute Care Hospitals (Doctoral dissertation).

Kuijpers, E., Kooij, D., \& van Woerkom, M. (2020). Align your Job with Yourself: The Relationship between a Job Crafting Intervention and Work Engagement, and The Role of Workload. Journal of occupational health psychology, 25(1), $1-10$.

Kurtipek, S., \& Gungor, N. (2019). Individual Innovation: A Research on Sports Manager Candidates. Journal of Education and Learning, 8(1), 264-271.

Lara, M. (2019). The Effects of Nurses' Perception of Their Personal-Organizational Culture Fit, and Individual Innovation on Employee Engagement (Doctoral dissertation, Alliant International University). 
Le Blanc, P., González-Romá, V., \& Wang, H. (2020). Charismatic Leadership and Work Team Innovative Behavior: the Role of Team Task Interdependence and Team Potency. Journal of Business and Psychology, 6 (1), 1-10.

Lin, H., \& Lee, Y. (2017). A Study of The Influence of Organizational Learning on Employees' Innovative Behavior and Work Engagement by a Cross-Level Examination. Eurasia Journal of Mathematics, Science and Technology Education, 13(7), 3463-3478.

Listau, K., (2017). Work Engagement: A Study of the Relationship between Work Engagement and the Work-Home Interaction. Scandinavian Journal of Work and Organizational Psychology, 2(1): 4, 1-13.

Mac-Rizzo, D. (2020). Examining The Relationship between the Use of Antipsychotic Medications and Organizational culture and Processes in Pennsylvania Nursing Homes:A uantitative Correlational Study (Doctoral dissertation, North central University).

Naidoo, P., \& Martins, N. (2014). Investigating the Relationship between Organizational Culture and Work Engagement. Problems and perspectives in Management Journal, 12 (4), 433-441.

Polit, D., Beck, C., \& Hungler, B. (2001). Essentials of Nursing Research: Methods, Appraisal, and Utilization. Nurse Researcher Journal, 13(4), 91-93.

Pourtaheri, N., \& Aalaee, M. R. (2016). Studying The Effect of Components of Organizational Culture on
Knowledge
Management in EducationalTreatment Hospitals of Kerman. International Journal of Medical Research \& Health Sciences, 5(7), 8-34.

Radwan, S.(2019). Organizational Support and Work Engagement among Head Nurses at Main Mansoura University Hospital. Unpublished master thesis, Faculty of nursing, MansouraUniversity,55-90.

Rothmann, S. (2017). Employee engagement. The Wiley Blackwell handbook of the psychology of positivity and strengths-based approaches at work. John Wiley \& Sons. Available at: https://www.wiley.com

Sánchez $\square$ Báez,E., nández $\square$ Serrano, J.,\&Romero,I.(2020). Organizatio nal Culture and Innovation in Small Hospital in Paraguay. Regional Science Policy \& Practice Journal, 12(2), 233- 247.

Sanders, K.,\& Shipton, H.(2015). The relationship between Transformation Leadership and Innovative Behavior in a Healthcare Team: A Team Learning Versus A Cohesion Perspective. European Journal International Management, 6 (1), 83-100.

Sarmad, M., \& Bashir, S. (2016). Impact of Nurses' Innovation on Patients'Satisfaction; Occupational Focus on Spirituality at Work as Moderator. Abasyn Journal of Social Sciences, 9(1), 69-85.

Schaufeli, W., Bakker, A., \& Salanova,M.(2006). TheMeasurem ent of Work Engagement with a Short Questionnaire: A CrossNational Study. Educational and 


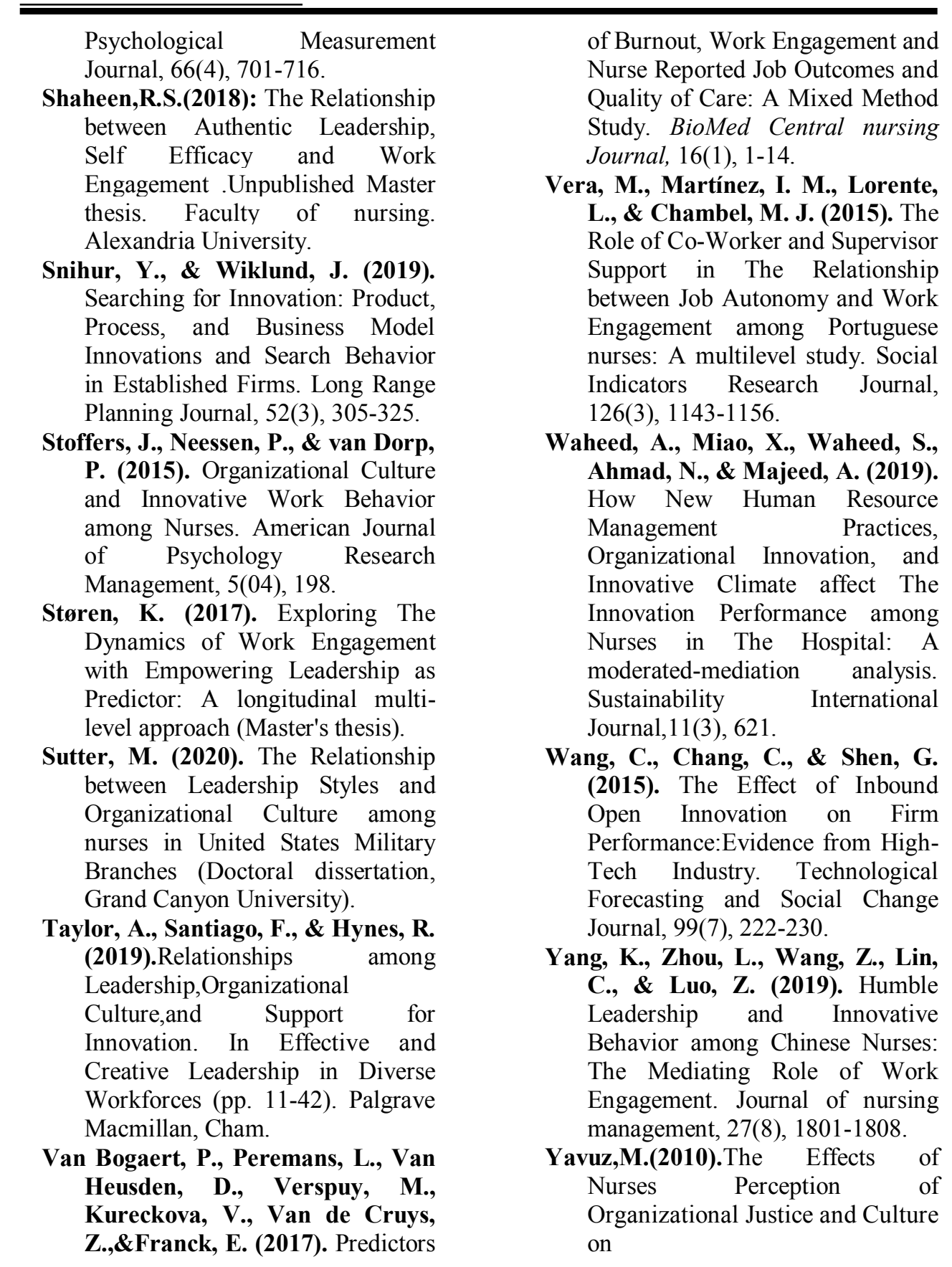

